American Journal of Infectious Diseases 5 (1): 21-25, 2009

ISSN 1553-6203

(C) 2009 Science Publications

\title{
Post Traumatic Meningitis in Neurosurgery Department
}

\author{
${ }^{1}$ Reza Malekpour-Afshar, ${ }^{2}$ Saeed Karamoozian and ${ }^{3}$ Hassan Shafei \\ ${ }^{1}$ Department of Pathology, Neurosciences Research Center, \\ Kerman University of Medical Sciences, Kerman, Iran \\ ${ }^{2}$ Department of Neurosurgery, Kerman Medical School, \\ Kerman University of Medical Sciences, Afzal Research Center, Kerman, Iran \\ ${ }^{3}$ Afzalipour Hospital, Kerman University of Medical Sciences, Kerman, Iran
}

\begin{abstract}
Problem statement: Post-Traumatic Meningitis (PTM) is a serious complication followed trauma. It sounds to have different pattern and characteristics. The aim of the current study was to determine the characteristics and outcome of PTM in referral neurosurgery department in Iran. Approach: During 5 years period-2003-2008, all records from meningitis patients in neurosurgery department in the unique referral trauma center in Kerman, Iran were evaluated by researchers, retrospectively. The PTM cases were selected and their data registered in the data collection form. The outcome of the disease as live or death considered, too. Analysis was conducted based on outcome and multivariable ANOVA was done to determine factor associated with death in PTM cases. Results: The incidence of PTM in head trauma patients estimated 3.1\% (95\% CI $=2.5-3.9 \%)$. The most frequent cases were male $89.7 \%$. Average of age was $28.4 \pm 17.2$ years. Klebsiella was the most common organism in CSF culture. Hospital staying time average in these patients was $25.7 \pm 15.8$ days. Surgery was done for $52(66.6 \%)$ cases. The fatality rate was $24.4 \%$, (95\% CI $=15.4-35.4)$. All death had undergone operation. Multivariable ANAOVA declared that blood sugar and CSF protein differed statistically between two groups, died and survived. Conclusion: PTM is an important phenomenon that has great mortality. Certainly, it needs antibiotic prophylaxis and immediate intervention and preventive services to reduce its morbidity and mortality rate.
\end{abstract}

Key words: Meningitis, trauma, neurosurgery, infection, complication, mortality

\section{INTRODUCTION}

Head trauma either open or blunt ones is one of the important cause of admission in neurosurgery ward. There are many complications after head injuries. Nonetheless infection is a serious problem which is threatening hospitalized patients and nosocomial meningitis is a potentially devastating complication of traumatic brain injury ${ }^{[1,6]}$. Head trauma created many conditions that enhanced the risk of intracranial infection ${ }^{[7]}$.The infectious agent gains access to the intracranial compartment by traumatic means. In these cases, the meningitis has to be classified as PostTraumatic Meningitis (PTM). Nosocomial meningitis characteristics vary from the usual meningitis. Although the nosocomial meningitis is rare, there is a wide range of factors associated with post traumatic meningitis. Palabiyikoglu and colleagues elucidated that traumatic wound infection, post-surgical wound infection and ventriculoperitoneal shunt were associated with $\mathrm{PTM}^{[10]}$. Korinek et al. ${ }^{[5]}$ substantiated the aforementioned factors and found other risk factors like CSF leakage, male sex, duration of surgery and neurological operation itself $\mathrm{f}^{[5]}$. Recent study determined CSF leakage was an independent risk factor and concomitant infections like as sinusitis, otitis and pneumonia increased the risk of $\mathrm{PTM}^{[19]}$.

Whereas nosocomial meningitis is a distinct category from community-acquired meningitis, in the unique study from Iran, we decided to describe the characteristics and outcome of patients with PTM and defined the factors associated to death in PTM patients.

\section{MATERIALS AND METHODS}

Setting: Shahid Bahoonar hospital is the greatest trauma center in Kerman province in Iran related to Kerman medical sciences university. Neurosurgery department and clinical ward are located in this hospital and it is the only neurosurgery center in the area. All

Corresponding Author: Reza Malekpour-Afshar, Department of Pathology, Neurosciences Research Center,

Kerman University of Medical Sciences, Kerman, Iran Tel: +989131405232 Fax: +983413221661 
patients with head injury referred to this center. It contains two neurosurgery wards and an equipped Intensive Care Unit.

Patients: All patients suspected to meningitis after trauma in Neurosurgery department were assessed by physician, exactly. Laboratory tests contain CBC, Serum FBS, CSF biochemical and cell analysis were checked and CSF culture was done for the patients with positive clinical and laboratory findings. Four culture media were used for CSF specimen: 1-blood agar, 2Chocolate Blood agar, 3- SUPPL-Thioglycollate and 4Eosin Methylene Blue culture media. All tests were performed in the standard condition in the hospital pathobiology laboratory. The clinical and laboratory data plus demographic characteristics were registered in the files.

Over a 5 years period, from March 2003 to March 2008, we collected the data related to PTM patients from their files and electronic database of hospital, retrospectively.

A definite diagnosis of bacterial meningitis was made by at least two of three: 1- evidence of a bacterial pathogen in one or more CSF cultures; 2- typical CSF findings of a decreased glucose concentration, increased lactate and protein concentrations and pleiocytosis with predominantly polymorphonuclear cells; and 3- classical clinical manifestations including fever, altered sensorium and signs of meningeal irritation $^{[3,13]}$.

We considered the outcome of PTM- survived or death-, too.

Statistical analysis: The SPSS version 15 was used to analyze the data. Results were described with percentage for categorical variable and mean \pm SD for continuous parameter. Independent t test was conducted to compared mean between survived and died. MannWhitney test and Chi squared test were used for rank and nominal data, respectively. Multivariate ANOVA was conducted to adjust the variable interrelation between two groups. P-value $<0.05$ was considered significant at every process of analysis.

\section{RESULTS}

During the five years of study a total of 11013 cases have been admitted from trauma, of which 2506 (22.7\%) had head trauma. Of the 2506 cases, 2065 $(82.4 \%)$ were males and $441(17.6 \%)$ were females. All of the head trauma cases were admitted to neurosurgery department. From them 78 patients $(3.1,95 \% \mathrm{CI}=2.5$ -
3.9) were suffered to meningitis that $70(89.7 \%)$ were males and $8(10.3 \%)$ were females. Their average age was $28.4 \pm 17.2$ their range of age was from 2-75 years. All of them were car accident victims. The most frequent organism involved was Klebsiella (27\%). There were $26(33.3 \%)$ negative culture positive clinical cases. Table 1 showed the pathogen found in culture media. The admission duration ranged from 574 days, its average was $25.7 \pm 15.8$ days. Surgery was done for $52(66.6 \%)$ cases. Age, hospital admission duration and CSF protein were the significance variable between surgical and non-surgical groups. The mean age was higher in surgical patients and they had stayed in hospital more than non-surgical patients. The CSF protein was higher in surgical group, too (Table 2).

Nineteen from $78(24.4 \%, 95 \%$ CI $=15.4-35.4)$ meningitis patients died. Among demographic variables age was significantly higher in death patients group $(\mathrm{t}=3.16, \mathrm{p}=0.004)$ Fig. 1 .

There was a significant difference between mortality and operation. All died had undertaken operation Fig. 2.

Table 1: The frequency of pathogen in study meningitis cases

\begin{tabular}{lcc}
\hline & Frequency & Percent \\
\hline S.aureous & 11 & 14.1 \\
S.epiderm & 5 & 6.4 \\
E.coli & 1 & 1.3 \\
Klebsiella & 21 & 26.9 \\
Acinetobacter & 8 & 10.3 \\
Alkalogen & 2 & 2.6 \\
Meningococc & 1 & 1.3 \\
Entrobacter & 1 & 1.3 \\
Citrobacter & 1 & 1.3 \\
Seratia & 1 & 1.3 \\
Negative culture & 26 & 33.3 \\
\hline Total & 78 & 100.0 \\
\hline
\end{tabular}

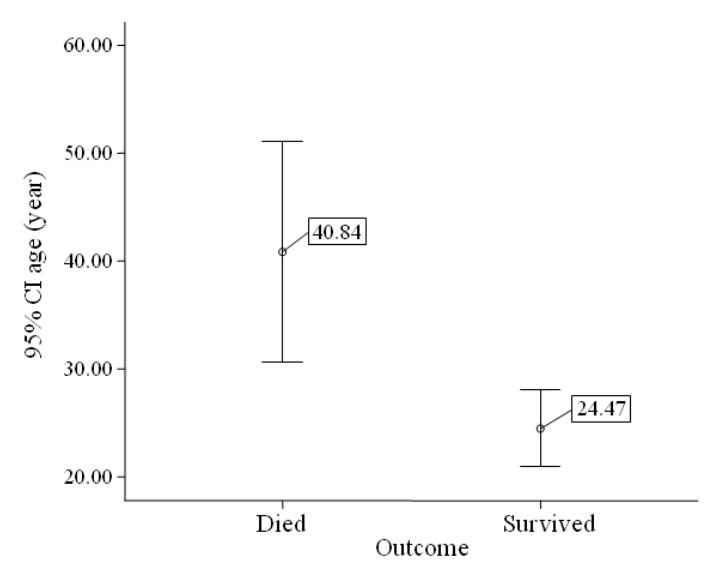

Fig. 1: Age differences between two survived and died patients 
Am. J. Infect. Dis., 5 (1): 21-25, 2009

Table 2: The significant variable between surgical and non-surgical patients

\begin{tabular}{llcrl}
\hline Variable & Group & Mean & \multicolumn{1}{c}{ SD } & p-value* \\
\hline Age & Surgery+ & 32.9 & 18.7 & $<0.001$ \\
& Surgery- & 19.6 & 8.7 & \\
Hospital admission & Surgery+ & 29.6 & 17.0 & $<0.001$ \\
duration & Surgery- & 17.4 & 7.9 & \\
CSF protein & Surgery+ & 208.9 & 214.3 & $<0.001$ \\
& Surgery- & 80.2 & 38.7 & \\
\hline
\end{tabular}

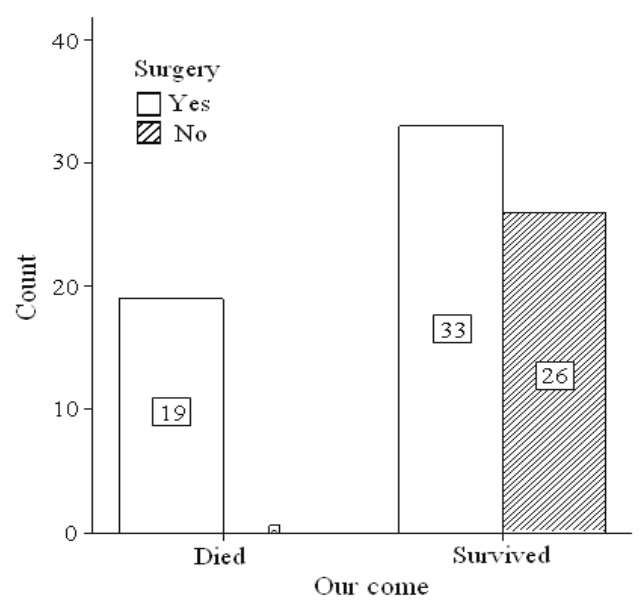

Fig. 2: Comparison of mortality between operational statuses

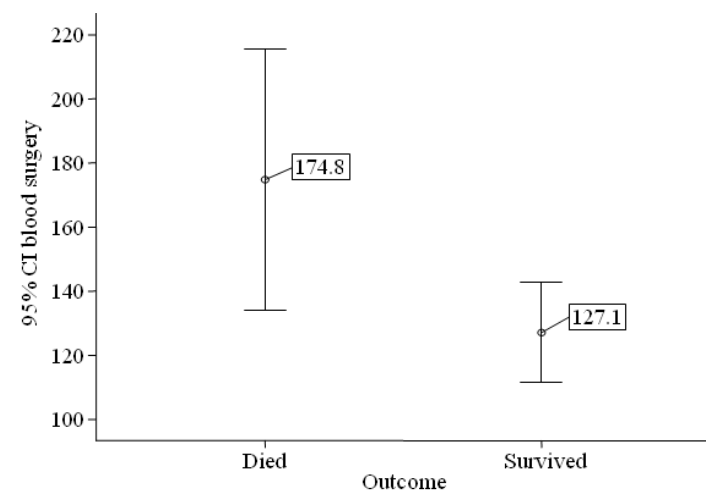

Fig. 3: The blood sugar mean compared in two groups $\mathrm{t}=2.293, \mathrm{p}=0.031$

In para-clinic finding, the blood sugar was higher in died group- $174.8 \pm 81.8 \mathrm{mg} \mathrm{dL}^{-1}$ vs $127.1 \pm 53.6$ Fig. 3, in contrast the CSF sugar was lower- $37.6 \pm 38.4$ vs $58 \pm 36.6$ - Fig. 4). The CSF protein was two fold higher in died, too Fig. 5.

Multivariable ANOVA was done to control of variable effect together. The blood sugar and CSF protein differed statistically between two groups and CSF sugar didn't have any significant differences between two groups (Table 3).
Table 3: Multivariate ANOVA between significant variable in two groups

\begin{tabular}{lrrrrrr}
\hline & Mean & SD & F & p-value & $\mathrm{R}^{2}$ & Power \\
\hline Blood sugar & & & & & & \\
Died & 174.8 & 81.8 & 7.470 & 0.008 & 0.108 & $77.0 \%$ \\
Survived & 126.9 & 54.2 & & & & \\
CSF protein & & & & & & \\
Died & 279.2 & 264.3 & 7.593 & 0.008 & 0.109 & $77.4 \%$ \\
Survived & 134.8 & 150.3 & & & & \\
CSF sugar & & & & & & \\
Died & 39.6 & 38.4 & 2.428 & 0.124 & 0.038 & $33.5 \%$ \\
Survived & 55.1 & 34.8 & & & & \\
\hline
\end{tabular}

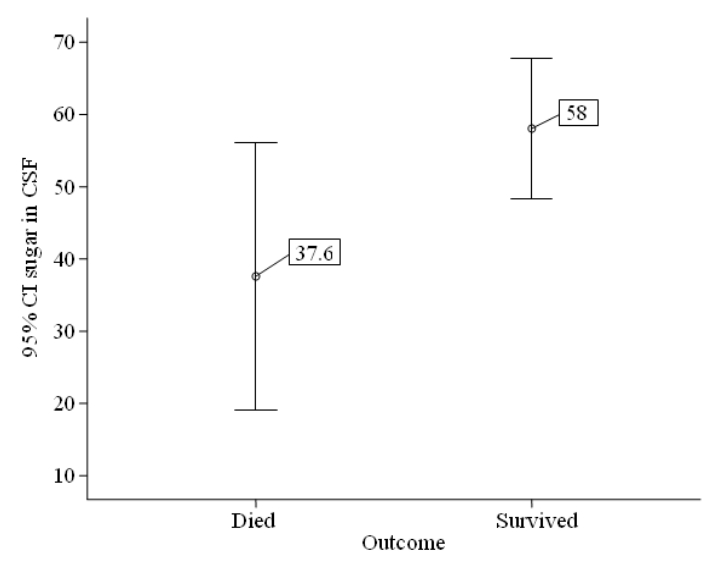

Fig 4: The CSF sugar mean compared in two groups $\mathrm{t}=2.085, \mathrm{p}=0.04$

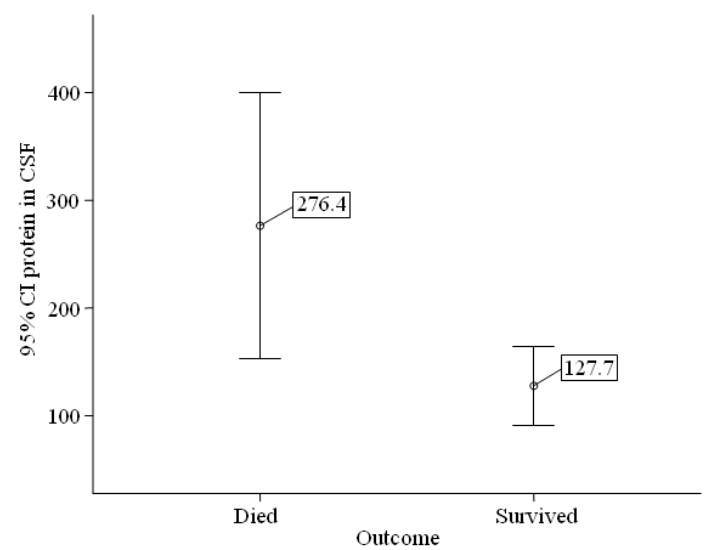

Fig. 5: The CSF protein mean compared in two groups $\mathrm{t}=3.213, \mathrm{p}=0.025$

\section{DISCUSSION}

Meningitis is one of the complications which may occur during the course of brain trauma and may markedly worsen outcome or result in death. Our finding determined that the incidence of PTM was 3.1\% and their fatality rate was $24.4 \%$. Many references 
introduced that up to $10 \%$ of patients with head trauma were complicated with meningitis ${ }^{[4,6]}$. The surgery is a risk factor for meningitis and mortality. In our recent study, $66.6 \%$ of meningitis cases had neurosurgery procedure before infection. Unfortunately, all persons who had died from meningitis had been operated after trauma. The incidence of post-surgical meningitis has been reported to $5 \%$ in many studies which patients received prophylactic antibiotics ${ }^{[8,15]}$. Beside it, many studies have declared the infection rate is significantly higher $(10 \%)$ without prophylaxis ${ }^{[9,17]}$. Finally, it is concluded prophylactic antibiotic therapy, preoperatively, in traumatic brain injury patients.

The most common offending pathogen was Kleabsiella in our finding, the Staphylococcus aureous and Acinetobacter were the followed. Other studies have reported S.aureous as the most frequent organism, a lot of results related to nosocomial and post-surgical meningitis ${ }^{[2,10,18,19]}$. Some other studies have demonstrated Streptococcus pneumonia is the most common pathogen in post-surgical meningitis ${ }^{[6]}$, however the incidence of S. pneumonia observed more in the children ${ }^{[12]}$.

Parodi and co-workers reported that the proportion of cases of nosocomial meningitis due to gram-negative organisms appears to be increasing, they revealed the entrobacters grew rapidly as the cause of nosocomial meningitis ${ }^{[11]}$. This study expressed our finding to Klebsiella. It seems Klebseilla is the important pathogen among post-traumatic meningitis. Tang and Chen discussed it previously ${ }^{[14]}$.

It is undoubted; neurosurgery following the head trauma is the main factor to suffer from meningitis and death. As told above the gram negative bacteria like Klebsiella and Acinetobacter are the most common organism involving leptomeninge. Our finding confirmed the results of previous studies. However we had some limitation in our study.

One of limitation was the retrospective data. We could not find some information from patients. The other problem in our study was the lack of anaerobic culture media. We could not used these media and detected anaerobic microorganisms like Pseudomonas. The advantages of our study were the precision of authors to collect data. To our knowledge, this is the first report about posttraumatic meningitis from Iran. Our data were collected from the referral head trauma center (Shahid Bahoonar hospital), thus we could generalized finding to our state and neighbor hood provinces. We recommend the multicenter prospective study to determine the exact outcome and associated factors of PTM.

\section{CONCLUSION}

The mortality of post traumatic meningitis is greater than other type of meningitis, but it is preventable. Prophylactic antibiotic therapy is considered necessary for some head trauma patients with especial indication.

\section{ACKNOWLEDGMENT}

The researchers thank to Dr Mohammad Arash Ramezani for helping to analyze and write this article and all staff in department of pathology in Shahid Bahonar hospital.

\section{REFERENCES}

1. Baltas, I., S.T soulfa, P. Sakellariou, V. Vogas, M. Fylaktakis and A. Kondodimou. 1994. Posttraumatic meningitis: Bacteriology, hydrocephalus and outcome. Neurosurgery, 35: 422-426. http://www.ncbi.nlm.nih.gov/pubmed/7800133

2. Dashti, S.R., H. Baharvahdat, R.F. Spetzler, E. Sauvageau, S.W. Chang, M.F. Stiefel, M.S. Park and N.C. Bambakidis, 2008. Operative intracranial infection following craniotomy. Neurosurg. Focus, 24: E10-E10. http://www.ncbi.nlm.nih.gov/pubmed/18518740

3. Durand, M.L., S.B. Calderwood and D.J. Weber, 1993. Acute bacterial meningitis in adults a review of 493 episodes. N. Engl. J. Med., 328: 21-28. http://www.ncbi.nlm.nih.gov/pubmed/8416268.

4. Jennett, B. and G. Teasdale, 1981. Open Injuries. In: Management of Head Injuries, Jennett, B. and G. Teasdale (Eds.). Davis Company, Philadelphia, pp: 193-210.

5. Korinek, A.M., T. Baugnon, J.L. Golmard, E.R. Van, P. Coriat and L. Puybasset, 2006. Risk factors for adult nosocomial meningitis after craniotomy role of antibiotic prophylaxis. Neurosurgery, 59: 126-133. http://www.ncbi.nlm.nih.gov/pubmed/16823308

6. Matschke, J. and M. Tsokos, 2001. Post-traumatic meningitis histomorphological findings, postmortem microbiology and forensic implications. Forensic. Sci. Int., 115: 199-205. http://www.journals.elsevierhealth.com/periodicals /fsi/article/PIIS0379073800003285/abstract

7. Mazzeo, A.T. and R. Bullock, 2005. Effect of bacterial meningitis complicating severe head trauma upon brain microdialysis and cerebral perfusion. Neurocrit. Care, 2: 282-287. http://www.ncbi.nlm.nih.gov/pubmed/16159076 
8. McClelland, S. and W.A. Hall, 2007. Postoperative central nervous system infection incidence and associated factors in 2111 neurosurgical procedures. Clin. Infect. Dis., 45: 55-59. http://www.ncbi.nlm.nih.gov/pubmed/17554701

9. Mindermann, T., W. Zimmerli and O. Gratzl, 1993. Randomized placebo-controlled trial of single-dose antibiotic prophylaxis with fusidic acid in neurosurgery. Acta Neurochir., 121: 9-11. http://www.ncbi.nlm.nih.gov/pubmed/8475816

10. Palabiyikoglu, I., E. Tekeli, F. Cokca, O. Akan, N. Unal, I. Erberktas, S. Lale and S. Kiraz, 2006. Nosocomial meningitis in a university hospital between 1993 and 2002. J. Hosp. Infect., 62: 94-97. http://www.ncbi.nlm.nih.gov/pubmed/16290316

11. Parodi, S., A. Lechner, R. Osih, P. Vespa and D. Pegues, 2003. Nosocomial enterobacter meningitis risk factors, management and treatment outcomes. Clin. Infect. Dis., 37: 159-166. http://www.ncbi.nlm.nih.gov/pubmed/12856206

12. Rudinsky, B., I. Stankovic, A. Kacerova, K. Holecko, L. Pevalova, M. Kalavsky, T. Sagat, P. Beno, E. Grey, M. Herbanska, V. Balik, I. Sulla, A. Harnicar, P. Jarcuska, F. Bauer, K. Kralinsky, O. Babela and V. Krcmery, 2006. Nosocomial postsurgical meningitis in children a 12-year survey comparing data from 1993-1998 with data from 19992004. Infect. Control Hosp. Epidemiol., 27: 788-790. http://www.ncbi.nlm.nih.gov/pubmed/16807864

13. Sigurardottir, B., O.M. Bjornsson, K.E. Jonsdottir, H. Erlendsdottir and S. Gudmundsson, 1997. Acute bacterial meningitis in adults. A 20-year overview. Arch. Intern. Med., 157: 425-430. http://www.ncbi.nlm.nih.gov/pubmed/9046894
14. Tang, L.M. and S.T. Chen, 1994. Klebsiella pneumoniae meningitis prognostic factors. Scand. J. Infect. Dis., 26: 95-102. http://cat.inist.fr/?aModele $=$ afficheN\&cpsidt $=4168713$

15. Tenney, J.H., D. Vlahov, M. Salcman and T.B. Ducker, 1985. Wide variation in risk of wound infection following clean neurosurgery. Implications for perioperative antibiotic prophylaxis. J. Neurosurg., 62: 243-247. http://www.ncbi.nlm.nih.gov/pubmed/3968563

16. Tunkel, A.R. and W.M. Scheld, 1990. Acute Infectious Complications of Head Trauma. In: Handbook of Clinical Neurology Head Injury, Vinken, P.J., G.W. Bruyn and H.L. Klawans (Eds.). Elsevier Science Publishers, BV Amsterdam, pp: 317-326.

17. Van, E.B., F.P. Bakker, D.H. van and B.A. Dijkmans, 1986. Infections after craniotomy: A retrospective study. J. Infect., 12: 105-109. http://www.ncbi.nlm.nih.gov/pubmed/3701096

18. Wang, K.W., W.N. Chang, C.R. Huang, N.W. Tsai, H.W. Tsui, H.C. Wang, T.M. Su, C.S. Rau, B.C. Cheng, C.S. Chang, Y.C. Chuang, P.C. Liliang, Y.D. Tsai and C.H. Lu, 2005. Post-neurosurgical nosocomial bacterial meningitis in adults microbiology, clinical features and outcomes. J. Clin. Neurosci., 12: 647-650. http://www.ncbi.nlm.nih.gov/pubmed/16023857

19. Weisfelt, M., B.D. Van de, L. Spanjaard and G.J. De, 2007. Nosocomial bacterial meningitis in adults a prospective series of 50 cases. J. Hosp. Infect., 66: 71-78.

http://www.ncbi.nlm.nih.gov/pubmed/17433493 